This item was submitted to Loughborough's Research Repository by the author.

Items in Figshare are protected by copyright, with all rights reserved, unless otherwise indicated.

\title{
Power handling of a photoconductive microwave switch
}

PLEASE CITE THE PUBLISHED VERSION

https://doi.org/10.1109/LAPC.2016.7807507

PUBLISHER

(c) IEEE

VERSION

AM (Accepted Manuscript)

LICENCE

CC BY-NC-ND 4.0

REPOSITORY RECORD

Kowalczuk, Emma K., R.D. Seager, and C.J. Panagamuwa. 2019. "Power Handling of a Photoconductive Microwave Switch". figshare. https://hdl.handle.net/2134/24324. 


\section{Power Handling of a Photoconductive Microwave Switch}

\author{
Emma K. Kowalczuk \\ Jaguar Land Rover, Banbury Road, Gaydon, UK \\ ekowalcz@jaguarlandrover.com
}

\author{
Rob. D. Seager, Chinthana. J. Panagamuwa \\ Wolfson School of Mechanical, Electrical and \\ Manufacturing Engineering, \\ Loughborough University, \\ Loughborough, UK \\ c.j.panagamuwa@lboro.ac.uk
}

\begin{abstract}
The power handling performance of a photoconductive microwave switch up to an RF input power of $44 \mathrm{dBm}(25 \mathrm{~W})$ is presented. The switch consists of a lightly doped die of silicon mounted over a gap in a transmission line. A $2 \mathrm{GHz}$ signal is applied through the switch and the $1 \mathrm{~dB}$ compression point is analysed.
\end{abstract}

Keywords - Photoconductive switch, optical control, fiber optic, silicon, linearity, microwave switch, reconfigurable antenna

\section{INTRODUCTION}

Reconfigurable antennas and circuits can bring many advantages to system performance such as multi-frequency and control over beam steering functionality. One key enabler to this technology is the switching mechanism employed to reconfigure the design. Typical figures of merit include low insertion loss, high isolation, fast switching speeds and minimal impact of biasing lines on RF performance. For high power applications, the additional criteria of high linearity and reliable operation as are also essential.

Types of microwave switches used in reconfigurable circuits include PIN/ varactor diodes, MEMS switches and photoconductive switches. The use of photoconductive switches has been proven in a variety of applications - the main benefit being that the RF performance of the system need not be compromised by the presence of DC biasing lines. Tawk et al. report the use of two silicon switches in a reconfigurable circular patch antenna [1]. In this instance silicon dice are illuminated directly via laser diodes in order to alter operating frequency. Phase shifters have also been demonstrated using optical switching [2]. In our research, a fiber optic cable is used to deliver illumination, which is generated in a remote location away from the RF circuitry.

Photoconductive microwave switches provide the advantage of control via a light source, allowing excellent thermal and electromagnetic isolation between the controlling optical beam and the controlled RF signal. This is an ideal scenario for high frequency applications, and can be a significant advantage in high power applications.

This paper focuses on reporting the power handling of the photoconductive switch in terms of power in versus power out to determine its suitability for high power applications. Due to the p-n junction in PIN and varactor diodes, these components are non-linear and produce distortion which is particularly prevalent at high powers leading to saturation in power out as power in is increased.

In the past MEMS have been limited to handling lower powers due to self-actuation and increased distortion at higher temperatures [5]. There are a few candidates recently that can handle RF (DC-40 GHz) power up to $10 \mathrm{~W}$, [6]. In this instance the reliability of the MEMS switch was compromised by the buildup of contaminants on the contact surface. To solve these reliability issues hermetic packaging is required which is expensive to implement [7].

The photoconductive switch presented here consists simply of silicon, and does not require the presence of a $p-n$ junction to work. The single tone third order harmonic linearity of this type of switch has been measured to be $63 \mathrm{dBm}$ at $2 \mathrm{GHz}$ [8]. The switch does not incorporate moving parts and so should be less expensive to manufacture and not suffer failure due to selfactuation under high power signals.

To determine the switch performance at higher powers, a $2 \mathrm{GHz}$ signal with up to $44 \mathrm{dBm}(25 \mathrm{~W})$ of power is applied to the switch and the $1 \mathrm{~dB}$ compression point is reported.

\section{SWITCH OPERATION}

The photoconductive switches consist of a die of phosphorus doped silicon, resistivity $>6000 \Omega \mathrm{m}$, attached between two lengths of copper microstrip line, Fig. 1. The switch is in its closed (ON state) when illuminated, which allows the RF signal to propagate through the silicon.

Once the light is removed the silicon behaves as an insulator and blocks the RF signal through the die. The switch does not incur any degradation in this process.

The transmission line topology has been optimised in terms of insertion loss and isolation in a previous study [8]. The switch is designed on $0.52 \mathrm{~mm}$ thick Rogers 3003 substrate which is mounted on an aluminum ground plane. The gap in the transmission line is $0.26 \mathrm{~mm}$, and the silicon die measuring $1 \mathrm{~mm} \times 1 \mathrm{~mm} \times 0.3 \mathrm{~mm}$ is attached directly over the gap using silver epoxy, (Fig. 1). 


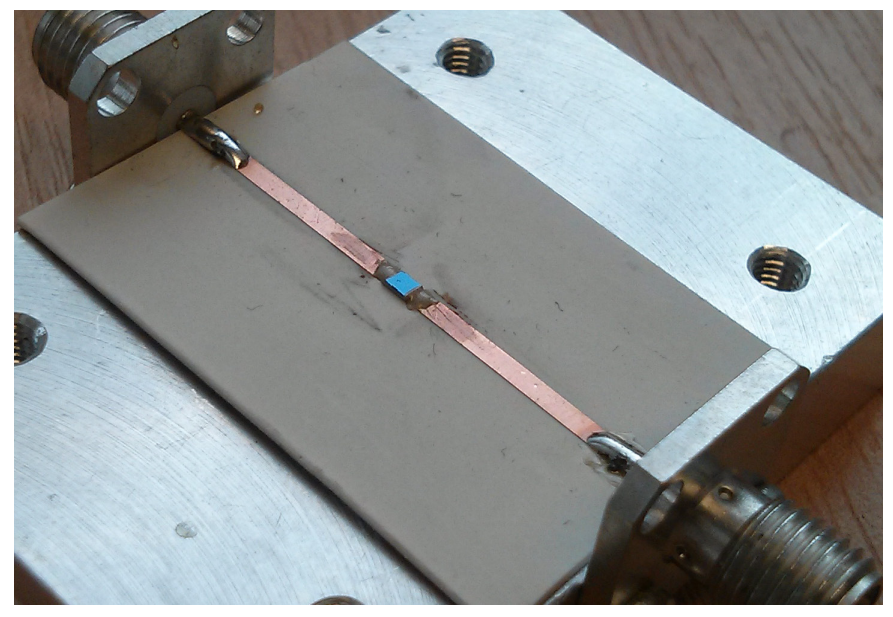

Fig. 1. Photoconductive microwave switch consisting of a gap in transmission line bridged by a $1 \mathrm{~mm} \times 1 \mathrm{~mm} \times 0.3 \mathrm{~mm}$ die of silicon

The switch is controlled using a laser diode system. Illumination from the remotely located laser diode is coupled into a $1 \mathrm{~mm}$ diameter fused silica fiber optic cable which is positioned directly over the silicon die. The wavelength of light used in this study is $980 \mathrm{~nm}$ and is delivered as a continuous wave with radiant flux of $200 \mathrm{~mW}$. The ambient temperature for all experiments is $24^{\circ} \mathrm{C}$.

\section{POWER HANDLING}

\section{A. Power handling measurement}

The measurement platform shown in Fig. 3 was used to observe the behavior of the switch at higher powers. Power output from port 2 of the switch at $2 \mathrm{GHz}$ is recorded up to 44 $\mathrm{dBm}$.

A CW signal is generated using a signal generator and is boosted to produce up to $44 \mathrm{dBm}$ by an external amplifier. To prevent damage to the amplifier a circulator including high power dummy load is used to absorb any reflected signal. A low pass filter with a $50 \mathrm{~dB}$ out of band rejection is used to block any harmonics generated by the amplifier from entering the switch.

A high directivity $22 \mathrm{~dB}$ directional coupler adapted from a design by Baek et al. [10] is used to couple a portion of the input signal entering the switch to determine an accurate reading for the input power. The output signal is fed into a 30 $\mathrm{dB}$ attenuator and then into the Spectrum Analyzer, Advantest $\mathrm{R} 3132$, to measure power at the fundamental frequency

\section{B. $1 \mathrm{db}$ Compression point}

A linear output power response is seen as input power is increased up to $36 \mathrm{dBm}$. The loss in the switch starts to increase at this point. Fig. 3 shows the high power performance of the switch compared to the extrapolated small signal performance of the switch. The $1 \mathrm{~dB}$ compression point is where the actual output signal of the switch is $1 \mathrm{~dB}$ below the extrapolated small signal gain of the switch (e.g. the switch's linear response).

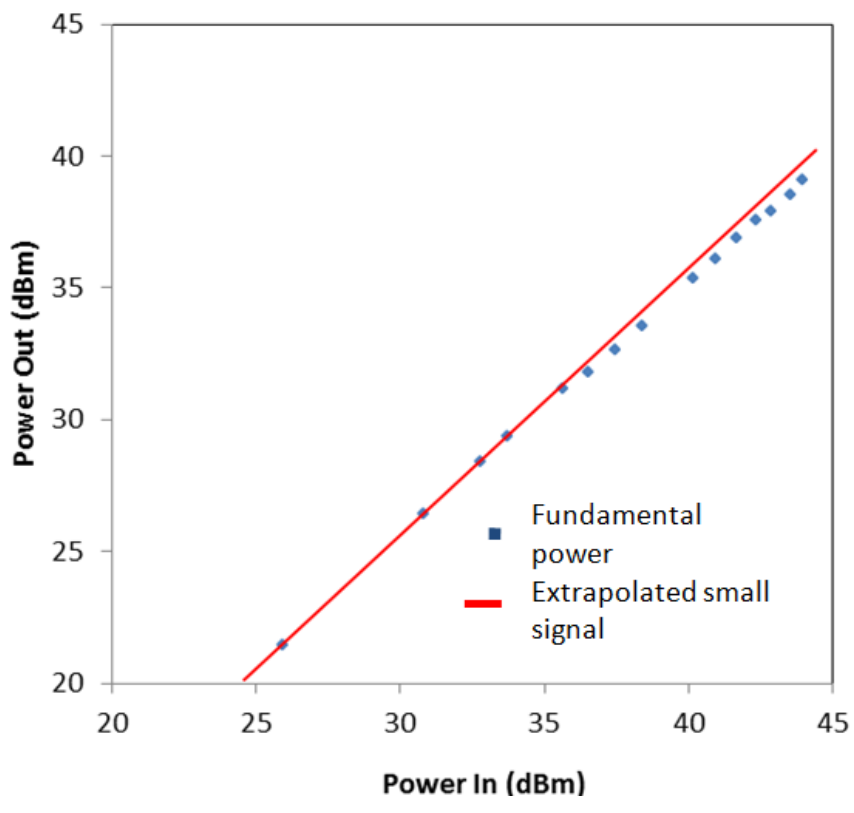

Fig. 2. Power handling response of the switch up to $44 \mathrm{dBm}$.

There is no saturation of the switch up to the maximum power tested, $44 \mathrm{dBm}$, Fig. 3. However at $42 \mathrm{dBm}$ input power the gradient of the power out is no longer unity, a $1 \mathrm{~dB}$ reduction in switch performance beyond this power level is evident when compared to small signal performance. It is expected that loss increases at these input powers as heating of the device and silver epoxy interconnect affects performance.

Through inspection of the switch post measurement, the silver epoxy element appears to have degraded from the increases in heat. In the future, possible alternatives to the silver epoxy interconnect such as wirebonding and surface mounting to the transmission line itself can be investigated. These methods, particularly surface mounting, reduce the resistance encountered by the RF signal as solder connections are more electrically and thermally conductive than silver loaded epoxy

Further testing with a higher power amplifier and tests for insertion loss at high powers will reveal how the temperature build up in the device affects insertion loss.

\section{CONCLUSION}

Initial high power measurements up to $44 \mathrm{dBm}(25 \mathrm{~W})$ at 2 $\mathrm{GHz}$ are presented. The $1 \mathrm{~dB}$ compression point is calculated to be $36 \mathrm{dBm}$. Saturation of the switch is not observed under these conditions, demonstrating the high power handling potential of the photoconductive microwave switch. With better interconnect design, it may be possible to increase the $1 \mathrm{~dB}$ compression point beyond $36 \mathrm{dBm}$. 


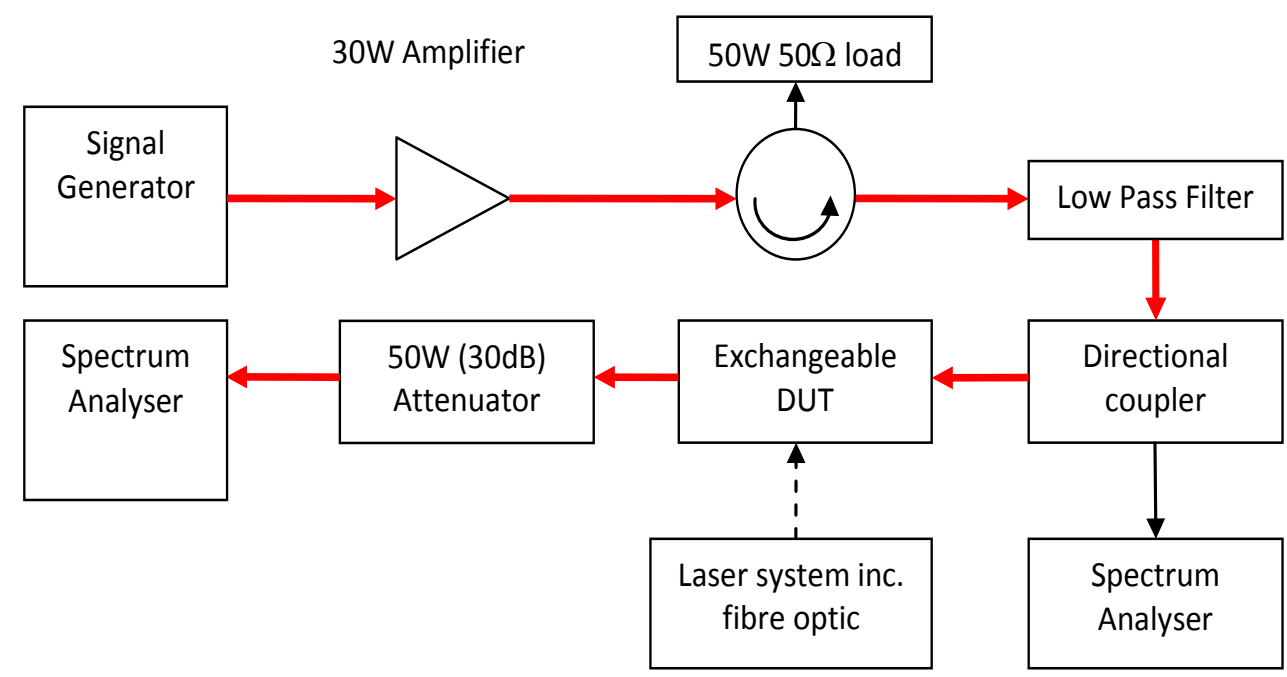

Fig. 3. Power handling and single tone linearity measurement setup

\section{REFERENCES}

[1] Y. Tawk, A. R. Albrecht, S. Hemmady, G. Balakrishnan and C. G. Christodoulou, "Optically Pumped Frequency Reconfigurable Antenna Design", IEEE Antennas and Wireless Propagation Letters, vol. 9, pp. 280-283, 2010

[2] A. Chauraya, C. J. Panagamuwa and J.C. Vardaxoglou "Beam Scanning Antenna with Photonically Tuned EBG Phase Shifters" IEEE Antennas and Propagation Society International Symposium 2006, pp. 2283, July 2006

[3] Radant MEMS "RMSW100HP High Power MEMS," www.radant.com, last accessed Jan. 2015

[4] G. Crusats, L. Jofre, and N. Biyikli, "RF MEMS Integrated Frequency Reconfigurable Annular Slot Antenna," IEEE Trans. Antennas Propagat. Vol. 58, No. 3, pp. 626-632, March 2010

[5] Y. Zhu and H. D. Espinosa, "Reliability of capacitive RF MEMS switches at high and low temperatures," Wiley Periodicals, pp. 317-328, 2004
[6] C. D. Patel, and G. M. Rebeiz, "An RF-MEMS switch for high-power applications,” IEEE MTT-S Int. Microwave Symposium Digest (MTT), pp.1-3, 2012

[7] K. Persson and K. Boustedt, "Fundamental requirements on MEMS packaging and reliability" Proc. On 8th International Symposium on Advanced Packaging Materials, pp 1-7, March 2002

[8] E. K. Kowalczuk, C. J. Panagamuwa, R. D. Seager, and J. C. Vardaxoglou, "Characterising the linearity of an optically controlled photoconductive microwave switch," Loughborough Antennas and Propagation Conference (LAPC), Nov. 2010

[9] E. K. Kowalczuk, , R. D. Seager, C. J. Panagamuwa, K. Bass and J. C. Vardaxoglou, "Optimising the performance of an optically controlled photoconductive microwave switch," Loughborough Antennas and Propagation Conference (LAPC), Nov. 2012

[10] D. Baek and Y. Kim, "Symmetric Microstrip interdigital capacitorcompensated high directivity directional-coupler," Microwave and optical technology letters, Vol 50, No 11, pp. 2801-2803, Nov. 2008 